\title{
Semantic Network Retrieval in TLE and TBI
}

\author{
Irfana $\mathbf{M}^{*}$, Himani B and Dollin J \\ Department of Speech Language Sciences, All India Institute of Speech and Hearing, India
}

Submission: November 16, 2018; Published: February 07, 2019

*Corresponding author: Irfana M, Department of Speech Language Sciences, All India Institute of Speech and Hearing, Mysore, India

Keywords: Mental lexicon; Semantic network; Neurological disordered; Population; Temporal lobe Epilepsy; Epilepsy disorder; Head Injury; Reaction time; Lobe Epilepsy; Computed tomography; Magnetic resonance; Percentage of accuracy; Frequency

Abbreviations: IA: Interactive Activation; TLE: Temporal Lobe Epilepsy; TBI: Traumatic Brain Injury; RT: Reaction Time; TLE: Temporal Lobe Epilepsy; EEG: Electroencephalography; CT: Computed Tomography; MRI: Magnetic Resonance Imaging; MRI: Magnetic Resonance Imaging; PA: Percentage of Accuracy; ERP: Event Related Potential

\section{Introduction}

Organization of mental lexicon in semantic network has been described using three major models including spreading activation model [1], semantic network model, and Interactive Activation (IA) framework [2,3]. As per these models, semantically related words are processed in increased activation spreading than unrelated words. However, truncated power distribution of activation happens if a word has multiple features sharing with other words. Priming allows testing the assumptions of semantic activation through network and utilized to comprehend the process in neurologically normal individuals [4]. However, neurological disordered population can equipped with handicapped representation of mental lexicon and retrieval among this population can be distorted.

Temporal Lobe Epilepsy (TLE) is the most common form of focal epilepsy which is a resultant of abnormal activity in the brain specifically in the temporal lobe which contributes to sensory loss, convulsions and loss of consciousness. Nevertheless, it is also responsible for causing speech and language disturbances. However, the severity of the problems is widely dependent upon the cause and nature of the disorder. Epilepsy disorder causes deviation in executive functions, reduced attention, memory impairment and is often associated with hampered language processing. A study showed intricate memory impairment on verbal intelligence tests and language impairment in people with epilepsy disorder [5]. There are different studies showing effect of epilepsy on language processing. One such study showing disturbances in semantic processing observed as a consequence of TLE. Results revealed that patients with TLE showed poor performance in matching and mismatching primes. Another study reveals the deficits in cognitive functions and semantic memory in patients with temporal lobe epilepsy $[6,7]$.
Traumatic head Injury (TBI) refers to injury to the head or brain caused due to any trauma or external force. Some of the major effects of TBI on communication and cognitive abilities are obscurity in planning and completing necessary daily activities, difficulty paying attention while speaking, difficulty in understanding abstract information and reduced social communication skills. Language deficits can be seen as major problems in such patients. Even minor head injuries can cause a wide range of cognitive deficits, expressive and receptive language deficits, psychological deficits and sensory deficits [8]. A study by concludes that the patients after traumatic brain injury present auditory processing disorders of varying degrees, involving the processes of decoding and organization. The mild TBI group demonstrates deficits in attention, non-verbal fluency, and verbal memory. They also demonstrate slower visual and tactile reaction time [9]. Whereas a study by SchmitterEdgecombe, Marks and Fahy in 1993 resulted that the closed head injury patients had slower Reaction Time (RT), overall, there were no significant group differences in the magnitude of either the automatic or attention component of semantic priming.

The present study aimed to analyse the word retrieval from semantic network in disordered population specifically patients with Temporal Lobe Epilepsy (TLE) and Traumatic Brain Injury (TBI) in temporal and/or parietal lobe. The objectives of the study were [1] Is speed and accuracy of word retrieval different for semantically associated from otherwise associated words [10] How far non- associated different from associated and semantically associated [3] How meaningfulness and frequency play part in semantic network representation[4] Is mental lexicon organization different in TLE and TBI [5] If yes, how different it is from neurologically normal population since the semantic 
memory system localized in distributed regions in temporal and parietal cortices [11]. In order to fulfil the objectives, there were three groups considered including neurologically normal, TLE and TBI and paradigm experiment comprised of semantic priming and associative priming tasks were used to measure RTs and accuracy of word retrieval from semantic network in these populations. Stimuli were presented visually since peripheral auditory processing can be compromised in this population.

\section{Materials and Methods}

Participants: A total of 27 participants were taken comprising of 10 patients with TLE, seven of them were diagnosed to have TBI and age and gender matched 10 normal individuals. All the participants were native Hindi speakers and literate with the mean age of 25-45 years. In TLE group, there were average six episodes of epileptic seizures and were under anti-epileptic drug use for 2-3 days. However, in TBI group, diagnosed to have lesions in the left parietal lobe and/or temporal lobe particularly lesion at ear level in most of the individuals while one of them had moderate subarachnoid hemorrhage involving left sylvian cistern. All the individuals were assessed on third day of their injury. Participants reported no premorbid speech, language, or cognitive disorders. All the participants had normal vision as per the informal assessment. Clinical reports of brain scans (Electroencephalography (EEG), Computed Tomography (CT) and Magnetic Resonance Imaging (MRI)) were used to identify the site and extent of lesion. The control group participants included considering no cognitive, linguistic or other associated deficits.

The paradigm experiment comprises of semantic priming and associative priming tasks. 60 pairs of words were chosen as stimuli for semantic priming task which comprised of equal number of meaningful and non-meaningful words. Different phonemes were randomly arranged to constitute non-meaningful Results lexemes. Meaningful words were further equally constituted based on frequency of usage in daily conversation. Similarly, non-meaningful words were categorised as frequent verses non-frequent orthographic representation. For the associative priming task 45 pairs of words were selected out of which 15 pairs each were semantically associated, associated and nonassociated. The semantically associated pictures chosen were typical and have same thematic category. However associated group of words were related based on forward, backward or symmetrical.

Written words were used for semantic priming task and associative priming task was performed using color pictures. Each pair of words was presented in black font over white background and the words were centrally aligned on computer display. Colored pictures of each word were selected with white background appeared randomly aligned in centre. Prime words were presented for $500 \mathrm{msec}$ followed by target where the target word appeared after a delay of $2000 \mathrm{msec}$ of prime. Response device used for the experiment was keyboard.

Procedure: The paradigm experiment (www. paradigmexperiments.com, version 2.5) used to administer both semantic and associative priming tasks. Randomized stimuli of both tasks were presented separately, and data was collected individually. For semantic priming task, participants were instructed to observe the prime and press right arrow if the following target was meaningful and press left arrow if the stimulus was non-meaningful. Associative priming task was administered in which the participants were expected to press right arrow if the primes were related and left arrow if the primes were unrelated. The responses were analysed based on the accuracy and the reaction time to complete the experiment. The control and clinical group responses were sorted out distinctively.

Table 1: Mean and standard deviation of reaction time and percentage of accuracy of semantic and associative priming tasks.

\begin{tabular}{|c|c|c|c|c|c|c|}
\hline \multirow{2}{*}{ Tasks } & \multicolumn{2}{|c|}{ Normal } & \multicolumn{2}{c|}{ TLE } & \multicolumn{2}{c|}{ TBI } \\
\cline { 2 - 6 } & $\begin{array}{c}\text { Mean \& SD } \\
\text { of RT }\end{array}$ & $\begin{array}{c}\text { Mean \& SD } \\
\text { of PA }\end{array}$ & $\begin{array}{c}\text { Mean \& SD } \\
\text { of RT }\end{array}$ & $\begin{array}{c}\text { Mean \& } \\
\text { SD of PA }\end{array}$ & $\begin{array}{c}\text { Mean \& } \\
\text { SD of RT }\end{array}$ & $\begin{array}{c}\text { Mean \& } \\
\text { SD of PA }\end{array}$ \\
\hline \multirow{2}{*}{ Frequent Meaningful } & 1920.67 & 97.21 & 5253.37 & 55.12 & 4312.29 & 62.97 \\
& 777.68 & 11.02 & 932.14 & 32.11 & 1022.32 & 36.22 \\
\hline \multirow{2}{*}{ Non-frequent Meaningful Frequent } & 2110.87 & 96.86 & 5496.88 & 50.68 & 4587.99 & 62.01 \\
& 998.99 & 19.54 & 928.11 & 33.76 & 975.52 & 33.21 \\
\hline \multirow{2}{*}{ Frequent Non-Meaningful } & 2354.32 & 87.77 & 5518.23 & 75.12 & 4894.43 & 77.66 \\
\hline \multirow{2}{*}{ Non-frequent Non-Meaningful } & 992.47 & 24.11 & 872.11 & 27.11 & 1118.02 & 30.54 \\
\hline \multirow{2}{*}{ Non-associative } & 3166.14 & 89.09 & 5912.63 & 84.41 & 5551.11 & 81.33 \\
& 1825.75 & 22.55 & 1992.55 & 25.08 & 1065.22 & 26.11 \\
\hline \multirow{2}{*}{ Semantically associative } & 3822.77 & 96.07 & 5106.63 & 69.45 & 5110.21 & 67.97 \\
& 654.32 & 15.77 & 509 & 28.53 & 412.43 & 19.45 \\
\hline \multirow{2}{*}{ Associative } & 2864.03 & 95.54 & 4232.11 & 70.11 & 4083.62 & 70.44 \\
\hline
\end{tabular}




\section{Open Access Journal of Neurology \& Neurosurgery}

Statistical analysis was carried out for each task of the experiment using SPSS (version 20). Mean and standard deviation were procured for the data of reaction time and Percentage of Accuracy (PA) of all three groups for both tasks. Results divulged prolonged reaction time for both the clinical groups compared to control group for both tasks. Mean percentage of accuracy was reduced in TLE followed by TBI. Table 1 depicts mean and standard deviation of reaction time and percentage of accuracy of semantic and associative priming tasks.

Table 2: Comparison of Reaction Time across groups.

\begin{tabular}{|c|c|c|c|c|c|c|c|c|}
\hline \multirow{2}{*}{ Tasks } & \multirow[t]{2}{*}{$\chi^{2}$} & \multirow[t]{2}{*}{$\mathbf{P}$} & \multirow{2}{*}{$\begin{array}{c}\text { Normal Vs TLE } \\
|\mathrm{Z}|\end{array}$} & \multirow[b]{2}{*}{$\mathbf{p}$} & \multirow{2}{*}{$\begin{array}{c}\text { Normal Vs TBI } \\
|\mathrm{Z}|\end{array}$} & \multirow[b]{2}{*}{$\mathbf{P}$} & \multicolumn{2}{|c|}{ TLE Vs TBI } \\
\hline & & & & & & & $|\mathbf{Z}|$ & $\mathbf{P}$ \\
\hline Frequent Meaningful & 20.6 & $.000^{*}$ & 4.186 & $.000^{*}$ & 4.762 & $.000^{*}$ & 1.3 & 0.2 \\
\hline Non-frequent Meaningful & 35.46 & $.000^{*}$ & 4.227 & $.000^{*}$ & 4.72 & $.000^{*}$ & 1.28 & 0.2 \\
\hline Frequent Non-Meaningful & 25.26 & $.000^{*}$ & 4.371 & $.000^{*}$ & 4.488 & $.000 *$ & 1.74 & 0.08 \\
\hline Non-frequent Non-Meaningful & 45.6 & $.000^{*}$ & 4.782 & $.000^{*}$ & 4.282 & $.000^{*}$ & 0.19 & 0.85 \\
\hline Non-associative & 21.04 & $.000^{*}$ & 4.236 & $.000 *$ & 3.903 & $.000^{*}$ & 1.72 & 0.09 \\
\hline Semantically associative & 20.06 & $.000^{*}$ & 4.161 & $.000^{*}$ & 4.092 & $.000^{*}$ & 1.9 & 0.06 \\
\hline Associative & 24.51 & $.000^{*}$ & 4.211 & $.000^{*}$ & 4.512 & $.000^{*}$ & 2.27 & 0.02 \\
\hline
\end{tabular}

* Significantly different

Table 3: Comparison of Percentage of Accuracy across groups.

\begin{tabular}{|c|c|c|c|c|c|c|c|c|}
\hline \multirow{2}{*}{ Tasks } & \multirow[t]{2}{*}{$\chi^{2}$} & \multirow[t]{2}{*}{$\mathbf{P}$} & \multirow{2}{*}{$\frac{\text { Normal Vs TLE }}{|\mathrm{Z}|}$} & \multirow[b]{2}{*}{$\mathbf{p}$} & \multirow{2}{*}{$\begin{array}{c}\text { Normal Vs TBI } \\
|\mathrm{Z}|\end{array}$} & \multirow[b]{2}{*}{$\mathbf{P}$} & \multicolumn{2}{|c|}{ TLE Vs TBI } \\
\hline & & & & & & & $|\mathbf{Z}|$ & $\mathbf{P}$ \\
\hline Frequent Meaningful & 21.39 & $.000^{*}$ & 4.35 & $.000^{*}$ & 3.774 & $.000^{*}$ & 0.2 & 0.85 \\
\hline Non-frequent Meaningful & 16.06 & $.001^{*}$ & 2.396 & $.017^{*}$ & 2.232 & $.026^{*}$ & 1.74 & 0.08 \\
\hline Frequent Non-Meaningful & 2.23 & 0.327 & - & - & - & - & - & \\
\hline Non-frequent Non-Meaningful & 2.06 & 0.356 & - & - & - & - & - & - \\
\hline Non-associative & 19.46 & $.000^{*}$ & 2.331 & $.020^{*}$ & 2.441 & $0.12^{*}$ & 1.74 & 0.08 \\
\hline Semantically associative & 15.8 & $.000^{*}$ & 2.17 & $.030^{*}$ & 2.217 & $0.21^{*}$ & 1.05 & 0.14 \\
\hline Associative & 20.23 & $.000^{*}$ & 2.451 & $.014^{*}$ & 2.005 & $.045^{*}$ & 1.85 & 0.06 \\
\hline
\end{tabular}

* Significantly different

Shapiro Wilk's test of normality was carried for each task respectively and no responses indicated normal distribution. Hence non-parametric tests were administered. Kruskal Wallis $\mathrm{H}$ test was used to see the effect of semantic priming task across three groups. Table $2 \& 3$ depict the statistical analysis of RT and PA within and across groups. Results showed significant difference in RT and accuracy for frequent and non-frequent meaningful and non-meaningful words between groups. Mann-Whitney U test administered to do pair wise comparison in each category.
There was a significant difference of RT and PA of control group from other two groups for frequent meaningful, non-frequent meaningful, frequent non-meaningful and non-frequent nonmeaningful words. And observed to have prolonged RT in TLE and TBI than control group and mean percentage of accurate response was higher in control than other groups. There was no significant effect of RT between TLE and TBI groups, however noted to have significantly higher accuracy rate in TBI than epilepsy group.

Table 4: Comparison of reaction time and percentage of accuracy across subcategories of semantic priming task.

\begin{tabular}{|c|c|c|c|c|c|c|c|c|}
\hline Groups & \multicolumn{4}{|c|}{ RT } & \multicolumn{4}{c|}{ PA } \\
\hline & \multicolumn{3}{|c|}{ Frequent Vs Non-frequent } & \multicolumn{2}{c|}{$\begin{array}{c}\text { Meaningful Vs Non- } \\
\text { meaningful }\end{array}$} & \multicolumn{2}{c|}{ Frequent Vs Non-frequent } & \multicolumn{2}{c|}{$\begin{array}{c}\text { Meaningful Vs Non- } \\
\text { meaningful }\end{array}$} \\
\hline & $|\mathbf{Z}|$ & $\mathbf{P}$ & $|\mathbf{Z}|$ & $\mathbf{P}$ & $|\mathrm{Z}|$ & $\mathbf{P}$ & $|\mathrm{Z}|$ & $\mathbf{P}$ \\
\hline Normal & 2.705 & $.007^{*}$ & 2.098 & $.036^{*}$ & 0.71 & 0.478 & 2.101 & $.038^{*}$ \\
\hline TLE & 2.232 & $.026^{*}$ & 2.101 & $0.41^{*}$ & 0.854 & 0.393 & 2.643 & $.008^{*}$ \\
\hline TBI & 2.294 & $.022^{*}$ & 1.979 & $.048^{*}$ & 0.854 & 0.393 & 2.232 & $.026^{*}$ \\
\hline
\end{tabular}

* Significantly different

As seen Table 4, subcategories of meaningful and nonmeaningful tasks were analysed within each group using Wilcoxon signed Rank test. Results divulged that significant effect of frequent words and it retrieved faster than nonfrequent in both meaningful and non-meaningful category in all the experimental groups. Similarly, meaningful words retrieved 


\section{Open Access Journal of Neurology \& Neurosurgery}

with greater accuracy and least RT in frequent and non- frequent words categories. No significant percentage of accuracy difference between the tasks in all three groups.

Effect of group within each subcategory of associative priming was assessed using Kruskal Wallis $\mathrm{H}$ test and as showed in Table 5 results revealed significant effect of groups. Further, pair wise comparisons were governed using Mann-Whitney U test. There was significant difference between normal and other groups for non-associative, semantically associated and associated prime pictures with least RT for normal group compared to other two. However, epilepsy and TBI groups were significantly different from each other only for non-associative prime.

Table 5: Comparison of reaction time across subcategories of associative priming task.

\begin{tabular}{|c|c|c|c|c|c|c|c|c|}
\hline \multirow{2}{*}{ Groups } & $\chi \mathbf{2}$ & $\mathbf{P}$ & \multicolumn{2}{|c|}{$\begin{array}{c}\text { Non-associative Vs } \\
\text { associative }\end{array}$} & \multicolumn{2}{|c|}{$\begin{array}{c}\text { Non-associative Vs Semantically } \\
\text { associative }\end{array}$} & \multicolumn{2}{c|}{$\begin{array}{c}\text { Associative Vs semantically } \\
\text { associative }\end{array}$} \\
\hline & & & $|\mathbf{Z}|$ & $\mathbf{P}$ & $|\mathrm{Z}|$ & $\mathbf{p}$ & $\mathbf{Z} \mid$ & $\mathbf{p}$ \\
\hline Normal & 20.067 & $.000^{*}$ & 3.589 & $.000^{*}$ & 2.232 & $.026^{*}$ & 2.634 & $.013^{*}$ \\
\hline TLE & 9.8 & $.007^{*}$ & 3.137 & $.002^{*}$ & 2.433 & $.015^{*}$ & 0.71 & 0.478 \\
\hline TBI & 7.916 & $.019^{*}$ & 2.232 & $.026^{*}$ & 2.561 & $.010^{*}$ & 1.717 & 0.086 \\
\hline
\end{tabular}

* Significantly different

Associative priming task was assessed within each experimental group using Friedman test and results showed that there was significant difference of RT between non-associative pictures from semantically associated and associated pictures in all three groups. Semantically associated pictures were retrieved significantly slowly than associative words in normal, however, there was no such variation in epilepsy and TBI groups. Percentage of accuracy was similar in both tasks for all three groups.

\section{Discussion}

In the current study, there was significant difference in the reaction time and accuracy between the control and experimental groups in both tasks. Though the electroencephalography and MRI findings of the participants did not show any significant lesion specifically in TLE group, the prolonged reaction time can be attributed to the diminished retrieval abilities. Similar results reported by Miyamoto et al. [6] and explained as disturbances of semantic processing in patients with TLE. Similarly, there was a difference seen in the accuracy of the tasks between normal and epilepsy participants revealing language processing difficulties in later. The reason for the deviation from the normal participants in the tasks was due to epilepsy affecting the retrieval and processing abilities. However, few of other studies explain no priming effect in temporal lobe epilepsy [12]. Similar results found in Event Related Potential (ERP) of temporal lobe epilepsy where non-matched had prolonged RT than matched words [6].

Present study results stated that TBI had prolonged RT and reduced accuracy as compared to normal group. Congruent with this, few studies explain reduced amplitude in ERP study in pediatric TBI survivors, comparative to the control group, demonstrating a decreased efficiency in the detection of semantic violations [13]. Similarly, long term patients of severe closed head injury had slower reaction times with no significant group differences in automatic or attention component of semantic priming [14]. Also, patients with early stage of moderate-tosevere TBI had reduced efficiency in ability to access semantic information [15]. Another ERP study used N400 response for assessing the linguistic processing and revealed a significantly smaller N400 response in the unrelated condition compared to congruent and incongruent categories in TBI [16].

Effect of frequency and meaningfulness had seen in all groups. RT of frequently occurring and meaning full words were reduced as compared to the counterparts. However evident variation of PA was seen in meaningfulness. This has been studied in neurologically normal group and reported in different language speakers $[17,18]$. As per the present study, similar results obtained in both neurological normal and disordered populations which was reported in aphasics in literature $[19,20]$.

Moreover, relation of words in mental lexicon plays major part in processing duration and it was shown to have declined RT, however there was no difference in PA in any of the group. This is in agreement with spreading activation model [1] which explains the processing based on the shared features. Faster retrieval of frequently occurring orthographical representation firm the representation of spreading activation. Semantic features including both semantically related and associated words were processed faster than non- associated. This explains the activation of nodes in the semantic network, where the stronger network as explicated in semantic network model. Furthermore, this result in consistent with IA framework [13], integration of semantic and associative priming effect to IA framework well illustrated [18]. However, associated words had reduced RT than semantically related, and this can be considered as a clarified picture of priming effect [10].

Most of these results pattern were following in both neurologically normal and disordered population, where TLE and TBI had taken comparatively prolonged time for retrieving from the mental lexicon except the differentiated processing of semantically related and associated words. Disturbed neurological network demand prolonged processing time in these groups $[7,9]$ and it is possible to perceive the significance of parietal and temporal lobe in semantic network since it demanded in present studied disordered population [11]. 


\section{Open Access Journal of Neurology \& Neurosurgery}

\section{Conclusion}

Semantic and associative priming effects were studied in neurologically normal and disordered populations. Reaction time and percentage of accuracy were measured among these population and results were appeared to be imperative to the representation of semantic organization specifically for neurologically disturbed population. Frequency and meaningful effect had contemplated along with semantic feature similarity. This can be highlighted during rehabilitation of these kind of populations who has difficulty to retrieve words. Particularly, initial sessions of communication therapy can be included words those are frequently used in their language which are meaningful, also strongly associated words can be considered as token to get better results. This can ease the speech out which build self-confidence especially when the incident creates psychological trauma in this patient.

\section{References}

1. Murai Y, Adachi K, Koketsu K, Teramoto A (2011) Indocyanine green videoangiography of optic cavernous angioma - case report. Neurol Med Chir (Tokyo) 51(4): 296-298.

2. Alafaci C, Grasso G, Granata F, Cutugno M, Marino D, et al. (2015) Cavernous malformation of the optic chiasm: an uncommon location. Surg Neurol Int 6: 60.

3. Scholz M, Harders A, Lücke S, Pechlivanis I, Engelhardt M, et.al. (2008) Successful resection of the recurrence of a cavernous malformation of the optic chiasm. Clin Ophthalmol 2(4): 945-949.
4. Iwai Y, Yamanaka K, Nakajima H, Miyaura T (1999) Cavernous angioma of the optic chiasm--case report. Neurol Med Chir (Tokyo) 39(8): 617-620.

5. Rotondo M, Natale M, D Avanzo R, Pascale M, Scuotto A (2014) Cavernous malformations isolated from cranial nerves: unexpected diagnosis? Clin Neurol Neurosurg 126: 162-168.

6. Panczykowski D, Piedra MP, Cetas JS, Delashaw JB Jr (2010) Optochiasmatic cavernous hemangioma. Br J Neurosurg 24(3): 301-302.

7. Hempelmann RG, Mater E, Schröder F, Schön R (2007) Complete resection of a cavernous haemangioma of the optic nerve, the chiasm, and the optic tract. Acta Neurochir (Wien) 149(7): 699-703.

8. Meng C, Bi Z, Jiang H, Jing Y, Wang J (2015) [Eight cases of cavernous hemangioma of the optic chiasm]. Zhonghua Yan Ke Za Zhi 51(12): 907-911.

9. Marnat G, Gimbert E, Berge J, Rougier MB, Molinier S, et al. (2015) Chiasmatic cavernoma haemorrhage: to treat or not to treat? Concerning a clinical case. Neurochirurgie 61(5): 343-346.

10. Shibuya M, Baskaya MK, Saito K, Suzuki Y, Ooka K, et al. (1995) Cavernous malformations of the optic chiasma. Acta Neurochir (Wien) 136(1-2): 29-36.

11. Trentadue M, Pozzi Mucelli R, Piovan E, Pizzini FB (2016) Incidental optochiasmatic cavernoma: case report of an unusual finding on 3 Tesla MRI. Neuroradiol J 29(4): 289-294.

12. Venkataramana NK, Rao SA, Arun LN, Krishna C (2016) Cavernous malformation of the optic chiasm: neuro-endoscopic removal. Asian Neurosurg 11(1): 68-69.

Your next submission with Juniper Publishers will reach you the below assets

- Quality Editorial service

- Swift Peer Review

- Reprints availability

- E-prints Service

- Manuscript Podcast for convenient understanding

- Global attainment for your research

- Manuscript accessibility in different formats

( Pdf, E-pub, Full Text, Audio)

- Unceasing customer service

Track the below URL for one-step submission https://juniperpublishers.com/online-submission.php 